www.jmscr.igmpublication.org

Impact Factor 5.84

Index Copernicus Value: 83.27

ISSN (e)-2347-176x ISSN (p) 2455-0450

crossref DOI: https://dx.doi.org/10.18535/jmscr/v5i3.52

Journal Of Medical Science And Clinical Research

IGM Publication

An official Publication of IGM Publication

\title{
Determination of Unilateral Lung Function by Spirometry
}

\author{
Author \\ Dr S. Meenakshi \\ Prof \& HOD of Physiology Dept. SRM Dental College Ramapuram Bharathi Salai Chennai-89
}

\begin{abstract}
Patients with unilateral lung involvement were evaluated with Lateral Position Test (LPT).The severity of disease was quantitatively measured. This is the spirometric test which to a large extent accurately measures the percentage of differential ventilation of each lung. The paper discusses the method and its merits.
\end{abstract}

\section{Introduction}

Lareral Position Test (Bergan 1960 ${ }^{1}$ ) is a simple inexpensive, non-invasive safe, yet accurate method producing no discomfort to patients as in Bronchospirometry. This can replace the more elaborate radioactive gas techniques $\&$ broncho spirometry which are not usually available in all hospitals. Results with LPT obtained on a small series of patients with one lung involvement are presented in the report.

\section{Materials \& Methods}

A total no of 30 patients from Govt. Gen. Hospital were selected for the study. Patients were divided into 3 groups of 10 each. Group 1 consisted of those with left lung involvement. Group 11 with Right lung involvement and Group 111 with Bilateral disease. Patients who were sputum negative with acid fast bacilli on three consecutive days were selected with reference to their unilateral (left or right) and bilateral involvement based on clinical \& radiological assessments of their diseased condition. Disease wise distribution of patients among the three groups is given in Tble1.

Out of 30 patients selected for study 14 were females with age ranging from 31-46, height147$165 \mathrm{~cm}$ and weight from $36-58 \mathrm{~kg}$ ) and 16 were males with age ranging from 31-56, height from $152-178 \mathrm{~cm}$ and weight from $35-59.5 \mathrm{~kg}$. All smokers among males were asked to stop smoking $24 \mathrm{hrs}$ before they presented themselves for the tests.

Bergan's Lateral Position Test was performed on all patients as well as on 10 normal subjects to determine the average percentage of ventilation of each lung. Two females with a mean age of 29 years, height $162 \mathrm{~cm}$ and weight $52 \mathrm{~kg}$ and 8 males with a age of 39 years height of $172 \mathrm{~cm}$ and weight of $65 \mathrm{~kg}$ constituted normal subjects for comparison.

The patients lay in a comfortable supine position on a flat firm table, a nose-clip was placed and a mouth piece was held between teeth firmly to prevent leaks during changes in body position.

The mouth piece was attached to a three way valve with small dead space of $40 \mathrm{ml}$ and the 
subject breathed room air until the respiratory rate and breathing pattern had returned to the base line. At this point the subject was connected to the Expirograph which contained 100\% O2 and provided with $\mathrm{CO} 2$ scrubber.

When an even regular spirometric tracings had been obtained in supine position the patient was turned to the right lateral decubitous position without disrupting the connection with the spirometer. The patient remained in this position until an even regular spirometric tracing was obtained. The patient was turned to supine position where recording was continued until a definite expiratory level was established where upon the patient was turned to the left lateral decubitous position. when a definite expiratory level was established in this position, the patient was turned back to supine position for establishment of respiratory tracings.

During the whole procedure the patient was relaxed, the connection with the spirometer was not disrupted so that there was no leakage of air.

A successful examination consequently consists of continuous tracing with well established expiratory levels in the supine positions three times and in each of the 2 lateral positions once. All the expiratory levels in the supine positions should fall on the same straight line and from this line the changes in expiratory levels caused by the lateral decubitous positions were measured and the displacement recorded for each lung individually was expressed as the percentage of total change for both lungs. The percentage of ventilation of normal lungs in left lung involvement, right lung involvement, and in bilateral involvement are given in Figures1 a, b, c $\&$ d. The Lateral Position Test was repeated for each patient and the mean of the two results were used. After the completion of LPT within 3-7 mints the relative percentage of ventilation of each lung spirographic tracings of forced expiratory manouvere in supine, right lateral decubitous and left lateral decubitous positions were recorded to study in detail the relative impairment in volume and flow-rates of each lung. Three spirographic tracings in supine right lateral and left lateral positions were recorded. The patient was allowed to relax for 3-5 mints in between the recordings of spirometric tracings and the best tracing out of three was selected for studies in each position.

From the spirographic tracings in three positions forced expiratory vital capacity(FVC), Forced expiratory volume for first $0.75 \mathrm{sec}$ and $1 \mathrm{sec}$ $\left(\mathrm{FEV}_{0.75}\right.$ andFEV $\left._{1}\right)$ and their percentage

$\left(\mathrm{FEV} 0_{.75 \%}\right.$ and $\left.\mathrm{FEV}_{1 \%}\right)$ ) Mid expiratory flow rate (FEFR25-75\% and End expiratory flow rate, FEFR ${ }_{70-80 \%}$ and FEFR $75-85 \%$ and Mid expiratory time (MET) in mid, right and lateral lateral positions were determined. Mean Expiratory Flow-Rates (MEFR) at 25\%,50\% and 75\% of Vital capacity were also measured to plot the Mean expiratory flow -volume curve for both lungs. (Singh and Krishnamurthy1981 ${ }^{2}$ ).

\section{Results}

The normal percentage of ventilation of right lung was found to be $56.2 \%$ (sd2.6) that of left lung is $43.8 \%$ (sd2.6). The mean of all parameters for the three groups are presented to identify the relative degree of impairment of each lung. (TABLE 2,3, \&4). Comparitively reduced volume of of FVC, $\mathrm{FEV}_{.75} . \mathrm{FEV}_{1}$ and $\mathrm{FEVO}_{.75 \%}$ and FEV ${ }_{1 \%}$ and prolonged Mid-Expiratory Time (MET) indicate the relative degree of involvement of one particular lung. Similarly Mean Expiratory flowvolume curve in right lateral and left lateral positions is a sensitive measure of early changes in each lung function as shown in fig 2,3,4. Normals who performed the LPT produced results in $\mathrm{FVC}, \mathrm{FEV} 0_{.75}$ and $\mathrm{FEV}_{1}$ and their percentage etc are comparable to the actual figures in Hand Book of Physiology (Ofenn and Rahn1965 ${ }^{3}$ ). 


\section{JMSCR Vol||05||Issue||03||Page 18578-18582||March}

TABLE 1

$\begin{array}{lc}\text { DISEASE } & \text { GROUP1 } \\ \text { BRONCHIECTASIS } & 2 \\ \text { BRONCHOGENIC CARCINOMA } & 2 \\ \text { PUL. TUBERCULOSIS } & 1 \\ \text { FIBROTHORAX } & 1 \\ \text { PLURAL EFFUSION } & 1 \\ \text { EMPHYSEMA } & - \\ \text { LOBECTOMY } & 1 \\ \text { LUNG ABSCESS } & 1 \\ \text { MULTIPLE CYST } & 1 \\ \text { CONSOLIDATION } & - \\ \text { PNEMONIA, } & - \\ \text { ASTHMA } & - \\ \text { CORPULMONALE } & -\end{array}$

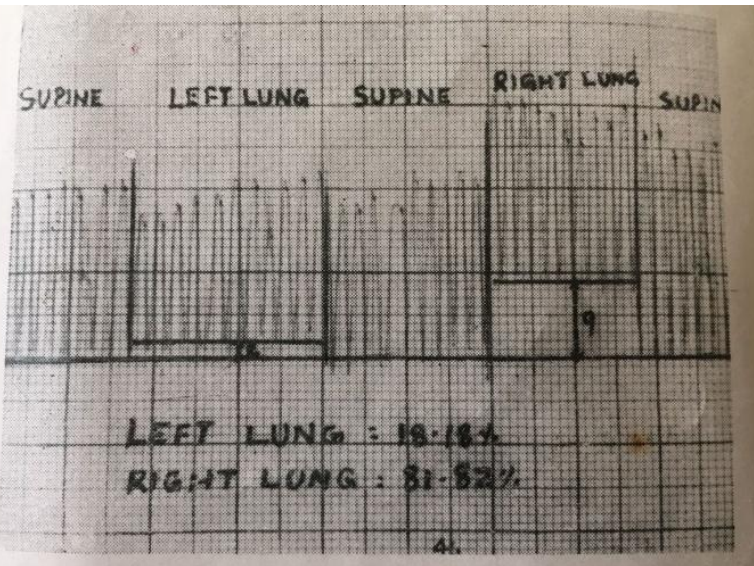

$1 b$ : Left lung more involved

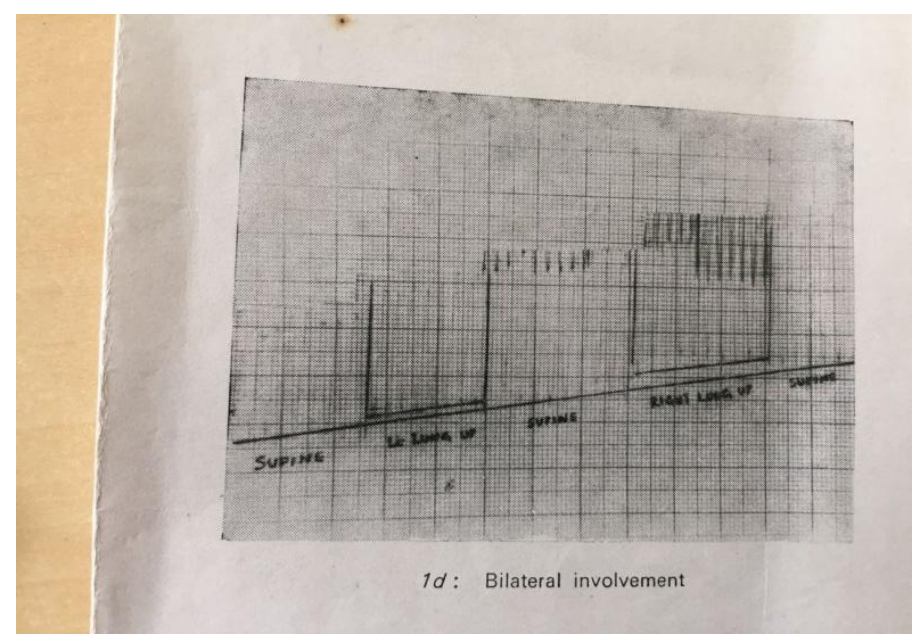

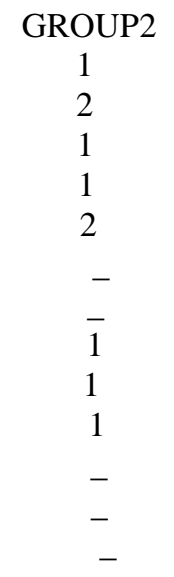

3

$-$

1-

- 3

$-$

$-$

$-$

$-1$

$-\overline{1}$
1
-
1




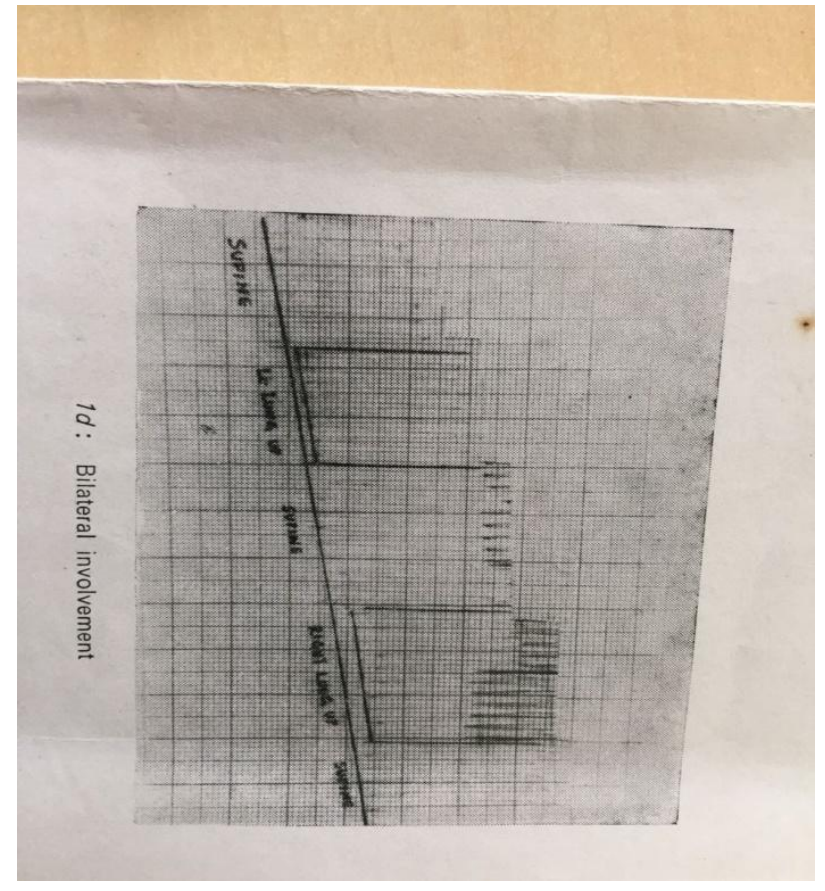

\section{Discussion}

The whole procedure is a simple spirometric test based on the observation that functional residual capacity (FRC) increases with change from supine to lateral position (Bergan1960). The FRC of the uppermost lung increases while the FRC of the dependent lung is unchanged or decreases only slightly and the relative changes in total FRC will be reflected over the expiratory tracings when shifted from supine to the uppermost position.

The forced vital capacity recorded when the subject is in right lateral position reflects the relative percentage of ventilation of lung volumes and flow -rates of left lung and that of the spirometric tracings for the right lung can be obtained with the subject lying on his left lateral position.

But when the recumbent normal subject changes to the right or left lateral position from supine, the changes produced in FRC are cancelled in their effect on vital capacity which showed no significant change in 3 positions. (Ofenn and Rahn $1965^{3}$ ). It will be noticed from table 2,3 that in unilateral disease the change in posture from supine to lateral positions bring about highly significant $(p, 0.001)$ reduction in lung volumes, flow-rates and percentage of ventilation of the involved lung depending upon the degree of involvement of that lung.
The displacement of end expiratory level from supine and in two lateral positions may be taken to indicate the mobility of mediastinum and the reduction in the degree of mediastinal mobility can be assessed in different type of diseases. In normals where the mediastinum is mobile there is a change in FRC of 330-360ml for the left lung( in right lateral decubitous position)and $390-420 \mathrm{ml}$ for right lung (in left lateral decubitous position)occurs. In Group 1 (left lung involvement) and in Group11 (right lung involvement) the degree of restriction of the mediatinal mobility bring about the severity of reduction in FRC.in Group 111 restriction of mediastinal mobility is more in parenchymal disease than the obstructive type of disease. A gross reduction in shift of FRC of only $90 \mathrm{ml}$ occurs in lateral positions.

Thus the displacement of end expiratory level from supine and in 2 lateral positions may be taken to indicate the mobility of the mediastinum and so the reduction in degree of mediastinal mobility can be assessed in different types of disease.

In normals where the mediastinum is mobile there is a change in FRC of 330-360ml. for left lung ( in right lateral decubitous positions)and 390-420ml for right lung (in left lateral decubitous position)In Group 1 (left lung involvement)and Group11 (right lung involvement)restriction of mediastinum in carcinoma is less than that with fibrosis. IN Bronchogenic carcinoma of one lung the change in FRC reduced to $210 \mathrm{ml}$ for left lung, $240 \mathrm{ml}$ for right lung whereas in unilateral tuberculosis FRC change to $150 \mathrm{ml}$ for left lungand $180 \mathrm{ml}$ only for right lung showing the increased restriction of mediatinum.

In $\mathrm{G}$ roup111 Fibrosing bilateral parenchymal disease restricts the mediastinal mobility more than the obstructive type of disease. A gross reduction in shift of FRC of only $90 \mathrm{ml}$ occurs in lateral positions.

In short fibrosis of either side with healed pulmonary tuberculosis or chronic suppuration leads to most restricted mediastinum but obstructive types of diseases like emphysema and asthma do not affect much the mediastinal 
mobility and bring about a change of $270-330 \mathrm{ml}$ in FRC in lateral positions. The number of subjects analysed for each type of disease is too small and these results can be taken only as preliminary observation. Further study on large number of patients are required to establish conclusively the results on lung functions observed by this procedure.LPT can be included as an important investigatory procedure in clinical practice. LPT can be performed in patients with more of asymmetric lung function to give a better estimate of the functioning of each lung has been confirmed by Hazlett $\left(1974^{4}\right)$ who correlated the results of LPT with those of Bronchospirometry.

It is a simple accurate, inexpensive and noninvasive technique for determination of unilateral lung function. It has been confirmed by Marion et al $\left(1976^{5}\right)$ who determined the unilateral ventilation by radio-isotope method using Xenon $^{133}$ and correlated the results with LPT determined by Spirometry. The references cited above do not provide the actual measurements of various parameters and hence comparative evaluation could not be made.

Sizable differences in measurments of the LPT can be present among normal subjects and in a given subject from test to test even though the conditions are standardized and rigidly controlled. Variations in LPT in relation to sex, age, weight and height and training procedures were determined by Stephen et al $\left(1980^{6}\right)$. but these factors did not contribute significantly to the variations observed. LPT is a useful method for evaluation of patients for lung resection as the test is useful in predicting unilateral lung function, Walkup $\left(1980^{7}\right)$.

LPT has its own limitations. This gives an estimate of one lung but not the lobar distribution of function. If the mediatinum is not free to move with changes in body positions allowing for lung volume shifts, then LPT may give unreliable results. Solomon $\left(1981^{8}\right)$ Also it measures the distribution of ventilation only and it is possible that the lung could have vascular compromise and be essentially without function and still be ventilated thereby causing LPT to overestimate the function of that lung Coope $\mathrm{r}\left(1981^{9}\right)$.In patients with extensive restrictive disease, underestimation of functioning of the disesed side occurs probably because of decresed compliance of the affected hemithorax leads to a disproportionately small changes in FRC when lung is uppermost.

\section{References}

1. Bergan, frank1960 a simple method of determination of the relative function of the right and left lung. Acta. Chirugica scand. Suppl 253. 58-63

2. singh hd. And krishnamurthyg. 1981. Mean expiratory flow-volume curve ind, $\mathrm{j}$, phy. Pharmacy. 25.1. 85-88

3. ofenn Wallace and rahn, herman 1965 effect of posture on lung volumes and sub divisions. Hand book of physiology. Respiration vol11. Sec3. American physiological society Washington DC 1965. 1363-1365

4. hazellet 1971 a simple inexpensive accurate method of studying separate functions of lung chest 59.3.276-279

5. marion jm. Anderson.po. lefrac ss. Seniorrm and jacobmh1976 unilateral lung function. Comparison of latrealposition test with radionuclide. Ventilation perfusion studies chest 69. 1. 59.

6. Stephen j.jay.robertb.stone hill. Saleem o. kiblawi and Norton james1980 variability of lpt in normals. amer. Rev. resp dis 121 1. $165-188$

7. walkup. Roberth. 1980 prediction of postoperative pulmonary function with LPT.chest.77.1.24-27

8. solomon.david a.1981 use of LPT and perfusion of lung scanin predicting mediatinal metastases

9. cooper.kevinr. 1981 reliability of lateral position test chest 79,4.494-49.5 